\title{
GIS-BASED MAPPING OF LOCAL CLIMATE ZONES USING FUZZY LOGIC AND CELLULAR AUTOMATA
}

\author{
I. Estacio ${ }^{1, *}$, J. Babaan ${ }^{1}$, N. J. Pecson ${ }^{1}$, A. Blanco ${ }^{1,2}$, J. E. Escoto ${ }^{2}$, C. K. Alcantara ${ }^{2}$ \\ ${ }^{1}$ Training Center for Applied Geodesy and Photogrammetry, University of the Philippines Diliman, Philippines - (icestacio, \\ jbbabaan,ngpecson, acblanco)@up.edu.ph \\ ${ }^{2}$ Department of Geodetic Engineering, University of the Philippines Diliman, Philippines - (jdescoto, caalcantara)@up.edu.ph
}

\section{Commission IV}

KEY WORDS: Urban Heat Island, Sky View Factor, Surface fractions, Surface Albedo, Roughness Length

\begin{abstract}
:
Because of the vague distinction between urban and rural areas, the Local Climate Zone (LCZ) scheme was developed to better analyze the effect of Urban Heat Island. To map the LCZs in a city, the World Urban Database and Portal Tool is used as conventional method. However, this requires the assignment of training areas for each LCZ, which entails local knowledge of the area and may introduce errors, as distinction between LCZ types through visual inspection is inconclusive. This paper aims to develop a methodology and GIS tool to enhance and automate the mapping of LCZs using seven LCZ properties (sky view factor, building surface fraction, pervious surface fraction, impervious surface fraction, building height, roughness length, and surface albedo), and apply it in Quezon City, Philippines which comprises varying land use and land cover. Fuzzy Logic was used to determine the membership percentage of $100 \mathrm{~m}$ cells to an LCZ type based on these properties. Cellular Automata was implemented using Python to derive the LCZ map from the fuzzy layers. Results show that seven out of ten built-up LCZs and five out of seven land cover LCZs were identified. Through visual inspection on a basemap, the mapped LCZs was confirmed to match with the features of the city. Land Surface Temperature (LST) derived from Landsat 8 showed that each LCZ type displayed temperatures consistent with those observed from literature. The developed methodology and tool is ready to be used in other cities as long as the input layers are generated.
\end{abstract}

\section{INTRODUCTION}

\subsection{The Local Climate Zones (LCZ) scheme}

Studies on Urban Heat Island (UHI) generally focus on the significant increase in temperatures in urban cities from the surrounding rural areas (Haashemi et al., 2016; Tzavali et al., 2015; Voogt and Oke, 2003). Reasons for the increase in temperatures are due to the incorporation of artificial materials such as concrete and asphalt which have higher emissivity, and the rise of tall buildings which trap heat in the underlying streets. These heat trapping impervious surfaces directly change the local climate in urban areas (Arathyram and Venugopala, 2012). Materials used in the walls of buildings and streets have high heat rates that store the heat throughout the daytime and emit heat during night-time (Algretawee et al., 2019).

A common problem of discussion in these UHI studies is the method on how to distinguish the urban from the rural areas. Using the administrative boundaries may introduce inaccuracies as the presence of urban elements does not generally end in the city boundaries. In fact, most towns surrounding cities are also urbanized, still lacking natural sceneries such as dense trees and bare soils. Also within an urban city, variations in the urban atmosphere can be observed as a result of the different urban forms and functions.

To solve this problem, Stewart and Oke (2012) introduced the Local Climate Zones (LCZ) scheme to classify urban and rural areas according to localized climate conditions (Figure 1). This scheme uses a 17 type zoning scheme composed of 10 built types and 7 land types, each of which has different geometric, surface cover, and thermal properties.

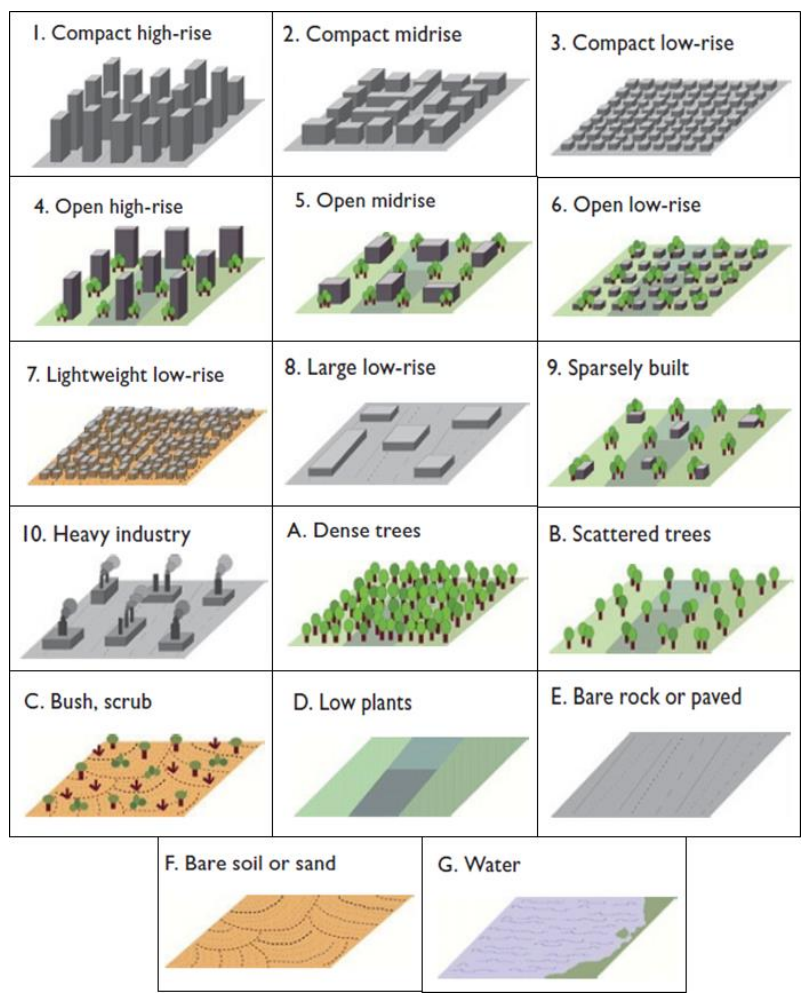

Figure 1. Local Climate Zones scheme: Built-types (1-10), Land Cover Types (A-G) (Stewart and Oke, 2012)

\subsection{Methodologies in Mapping LCZs}

The conventional method in classifying LCZs adopted by several studies is the World Urban Database and Portal Tool (WUDAPT) 
method (Bechtel et al., 2015). This method classifies a multiband Landsat 8 image into LCZ types using digitized training areas in Google Earth. To digitize the LCZ training areas, a familiarization of the area is at least needed such as building density, building heights, and the land cover types. The digitized training areas are then used as input in the SAGA GIS software where Random Forest algorithm is used to classify the Landsat image into different LCZ types. As this method needs local knowledge of the area and also the specifications of the different LCZ types, the digitization of training areas may introduce errors in the generated LCZ map. WUDAPT also needs the classification area to be at least $50 \mathrm{~km}$ in size, which makes it impossible to apply in just a single city. As an alternative to WUDAPT, several methodologies have been developed that employs GIS techniques. These methods use derived layers of geometric, surface cover, and thermal properties (e.g., Sky View Factor, Building Surface Fraction, Surface Albedo) to classify the LCZs.

A study by Unger et al., (2014) used a vector-based approach classification where lot areas are classified into LCZ types based on seven derived properties. An algorithm was developed that incorporates fuzzy and neighborhood rules to classify and aggregate lot areas to produce the LCZs of at least $500 \mathrm{~m}$ diameter. Bartesaghi Koc et al., (2017) also mapped LCZs derived from airborne remote sensing datasets. Classification of LCZ types was implemented using defined ranges of values for the different properties. The produced LCZ map however has pixels with undetected LCZ type and no neighbors of the same class. Wang et al. (2018) mapped the LCZs of Hong Kong by using only three LCZ properties and a land use map. Fonte et al. (2019) used properties derived from OpenStreetMap (OSM). Fuzzy Logic and a weighted combination method were used to incorporate all the derived layers. Majority filtering was implemented to remove noise and to cluster zones.

As LCZs are at least $500 \mathrm{~m}$ in diameter, aggregation needs to be incorporated in GIS-based mapping of LCZs. Low Pass filtering methods for aggregation favor larger zones and may remove smaller but more accurate zones. A cellular automata-based approach that takes into account the membership percentage of a pixel and its neighbors may generate more accurate description of LCZs.

\subsection{Objectives and Expected Output}

This study primarily aims to develop a GIS-based methodology to enhance and automate the mapping of LCZs using derived properties of the different LCZ types. Specifically, it aims to develop a GIS tool that generates LCZ classification of an area based on input property layers. Fuzzy Logic was used to obtain membership percentages of every pixel to an LCZ type and Cellular Automata was used to combine and aggregate the fuzzy layers. The daytime and night-time Land Surface Temperature (LST) for every LCZ type was also evaluated.

\section{METHODOLOGY}

\subsection{Study Area and Data}

The study site is Quezon City, a highly-urbanized city located at the northern part of Metro Manila, Philippines (Figure 2). It is the largest city in terms of land area (166.2 square $\mathrm{km}$.) in Metro Manila, covering more than $25 \%$ of the total area of the region. It is also the most populated city in the whole country.
This city was chosen because of its large area that has the most diverse land use among the cities in the metropolis. It also houses the only watershed in Metro Manila which comprises a variety of ecosystems including forest and swamp vegetation. The commercial center and business district of the city are located in its southern part, while the northern portion is primarily residential in nature.

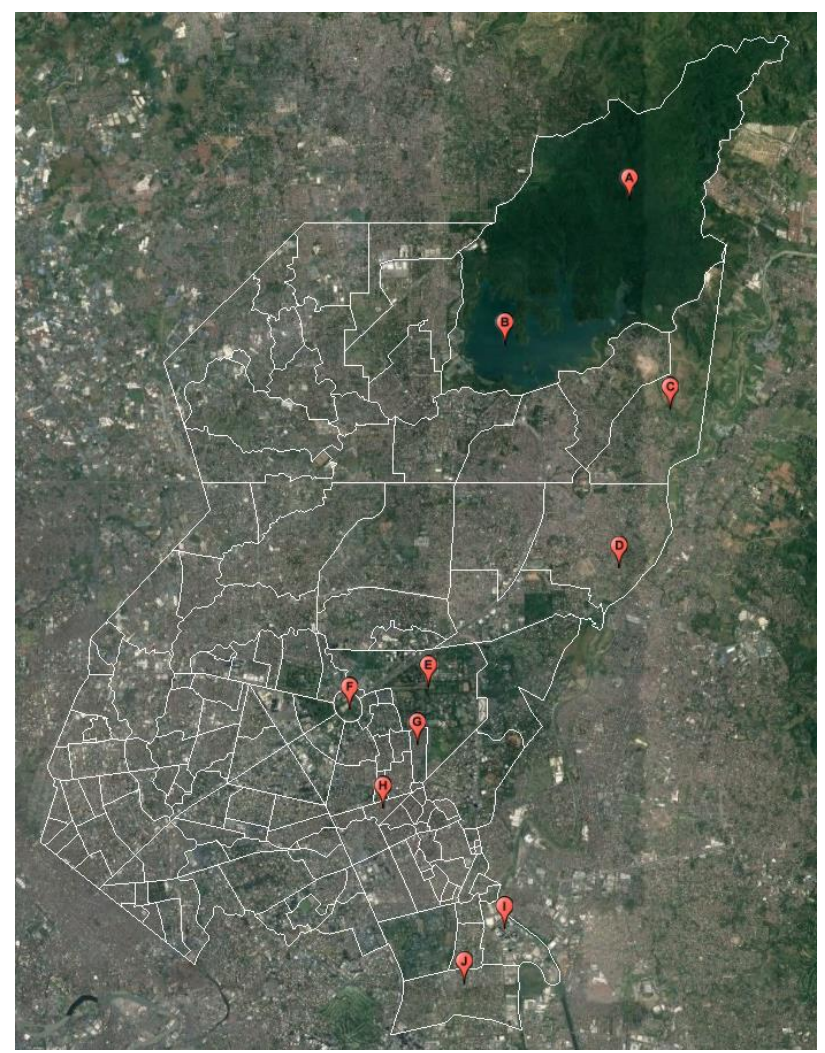

Figure 2. Google Earth Image of Quezon City: (A) La Mesa Watershed, (B) La Mesa Dam, (C) Bagong Silangan, (D) Barangay Batasan Hills (E) University of the Philippines Diliman, (F) Quezon City Memorial Circle, (G) Barangay Krus na Ligas, (H) Barangay Kamias, (I) Eastwood City, (J) Barangay Ugong Norte

\begin{tabular}{c}
\hline Data Used \\
\hline Quezon City boundary (.shp) \\
Building Footprint (.shp) \\
Roads (.shp) \\
Digital Terrain Model \& Digital Surface Model \\
Day \& Night LST Image \\
Landsat Image of Quezon City (February 5, 2019) \\
\hline
\end{tabular}

Table 2. Data Used in the Study

\subsection{General workflow}

Using the available datasets of Quezon City, seven property layers of LCZs were derived (Unger et al., 2014). Fuzzification of each LCZ type was implemented to derive the membership percentage of every pixel to each LCZ type. A cellular automata algorithm was implemented to derive the LCZ classification. Minimum mapping unit used for this study is $100 \mathrm{~m}$. Figure 3 shows the entire GIS-based methodology. 


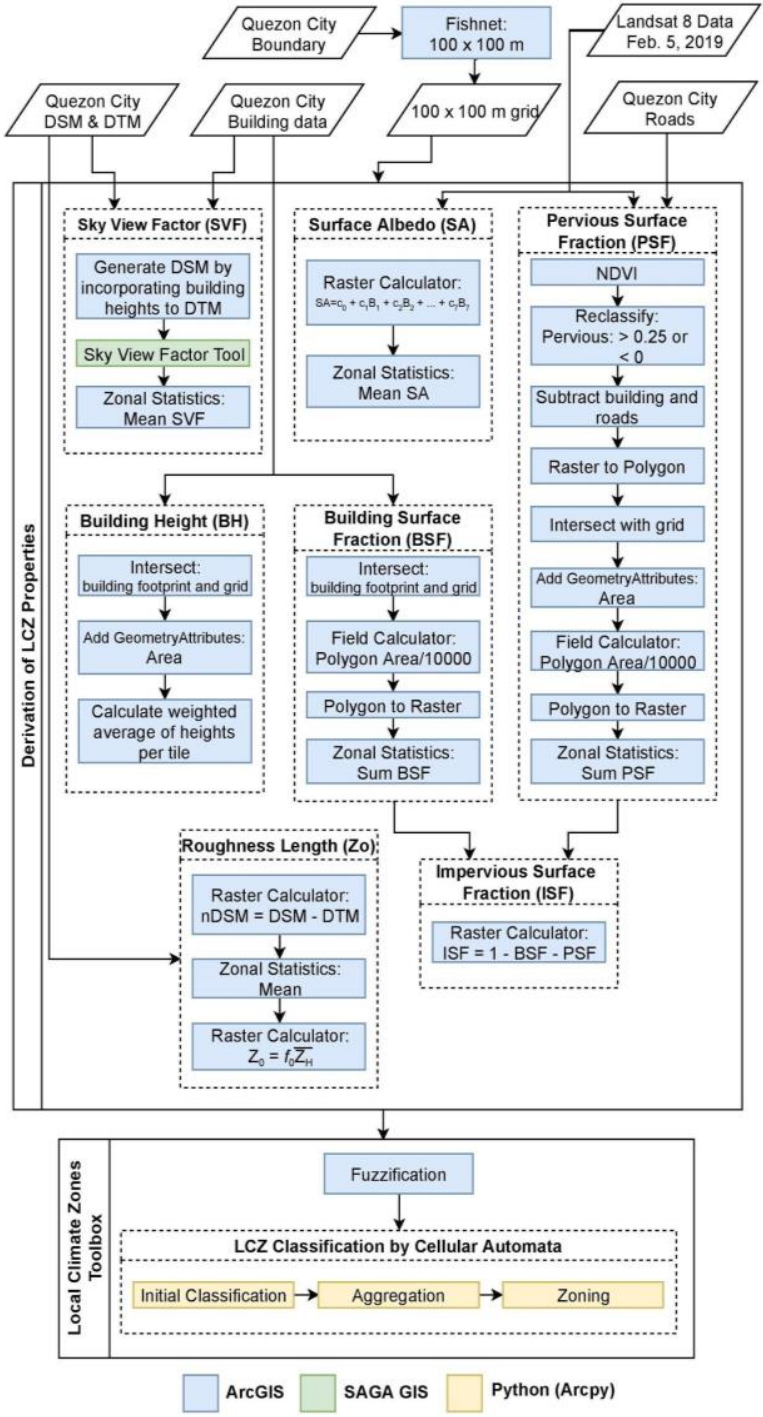

Figure 3. Workflow of the GIS-based mapping of LCZs

\subsection{Derivation of LCZ Properties}

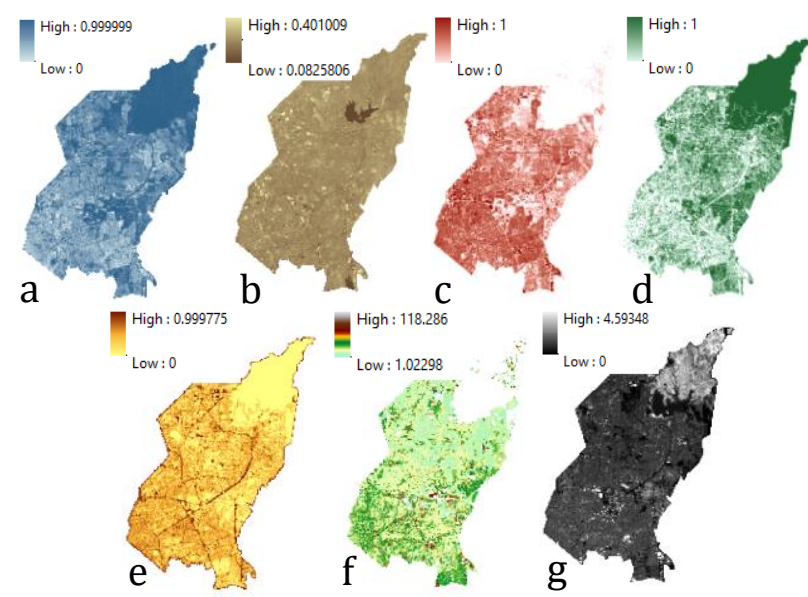

Figure 4. Derived layers of Local Climate Zones properties: (a) Sky View Factor (SVF), (b) Surface Albedo (SA), (c) Building Surface Fraction (BSF), (d) Pervious Surface Fraction (PSF), (e) Impervious Surface Fraction (ISF), (f) Building Height (BH), and (g) Roughness Length $\left(\mathrm{Z}_{0}\right)$
A grid covering the whole study area was generated using the "Fishnet" tool in ArcGIS software. This was then used to ensure that the $100 \mathrm{~m}$ pixels of all derived layers are aligned (Figure 4).

2.3.1 Sky View Factor (SVF): SVF is defined by Stewart and Oke (2012) as the ratio between the amount of visible sky from the ground to an unobstructed hemisphere. A Digital Surface Model (DSM) was generated in ArcGIS by incorporating the building heights to the DTM. It was assumed that the buildings have flat roofs and other features such as vegetation were neglected. The generated DSM was used as an input in the Sky View Factor Tool in SAGA GIS.

2.3.2 Surface Albedo (SA): Surface albedo, the fraction between the reflected and received solar radiation by a surface (Stewart and Oke, 2012), was calculated from the different atmospherically corrected Landsat 8 bands using the algorithm proposed by Baldinelli et al., (2017). It can be calculated using the equation:

$$
S A=c_{0}+c_{1} B_{1}+c_{2} B_{2}+\ldots+c_{7} B_{7}
$$

where SA is the surface albedo,

$\mathrm{B}_{\mathrm{i}}$ are band values,

$\mathrm{c}_{\mathrm{i}}$ are coefficient values (Table 1 ).

\begin{tabular}{|c|c|c|c|c|c|c|c|}
\hline $\mathrm{c}_{0}$ & $\mathrm{c}_{1}$ & $\mathrm{c}_{2}$ & $\mathrm{c}_{3}$ & $\mathrm{c}_{4}$ & $\mathrm{c}_{5}$ & $\mathrm{c}_{6}$ & $\mathrm{c}_{7}$ \\
\hline 0.043 & 0.082 & 0.064 & 0.173 & 0.114 & 0.237 & 0.252 & 0.034 \\
\hline
\end{tabular}

Table 1. Coefficients used for the calculation of Surface Albedo

2.3.3 Building Surface Fraction (BSF): BSF is the ratio of the building footprint areas and the minimum mapping unit. After intersecting the building footprint data and the grid, the BSF of each polygon was calculated. Then the BSF vector layer was converted to raster so that the total BSF per tile can be obtained by using the "Zonal Statistics" tool.

2.3.4 Pervious Surface Fraction (PSF): PSF is the percentage of pervious surfaces such as vegetated and permeable surfaces. To determine PSF, the Landsat data of the study area was used to derive an NDVI image. Based from Bartesaghi Koc et al. (2017), it was assumed that NDVI values greater than 0.25 are pervious surfaces. NDVI values below zero, which correspond to water, were also considered as pervious surfaces. Building and road polygons were converted to raster and were subtracted from the derived NDVI image to accurately extract pervious surfaces. The resulting raster was converted to vector and the PSF for every polygon was calculated using the "Field Calculator" tool in ArcGIS. The PSF vector layer was rasterized and the sum of PSF per tile was acquired using the "Zonal Statistics" tool.

2.3.5 Impervious Surface Fraction (ISF): ISF refers to the paved areas aside from buildings. This was derived by subtracting BSF and PSF from 1 using the "Raster Calculator" tool in ArcGIS.

2.3.6 Building Height (BH): The intersected building footprint data and grid layer was used to compute for the weighted average of building heights per tile with polygon area as weights. Weighted average was used to consider the spatial distribution of buildings within a pixel. 
2.3.7 Roughness Length $\left(Z_{0}\right)$ : The roughness length for the study area was estimated using the simple equation suggested by Oke (as cited in Hammond et al., 2011). $Z_{0}$ is proportional to the height of surface elements $\left(\mathrm{Z}_{\mathrm{H}}\right)$ by the empirical coefficient $f_{0}$. For this study, the value for $f_{0}$ was 0.1 which is generally used for surfaces according to Oke. $\mathrm{Z}_{\mathrm{H}}$ was derived from the mean difference between the DSM and DTM per tile. This was done to also include the height of other features such as trees.

$$
Z_{0}=f_{0} \overline{Z_{H}}
$$

\subsection{Fuzzification of LCZ Types}

Based on the derived seven properties, membership percentage of every $100 \mathrm{~m}$ pixel to an LCZ type was determined using the Fuzzy Logic tools in ArcGIS software. Each LCZ type has a range of values for each of the seven properties (shown in Table 2).

Linear membership type was used for the fuzzy membership. A pixel of value within the specified range has a membership percentage of 1 ; values outside the range have membership percentages depending on the nearness of the value to the range, with membership percentage reaching 0 at the \pm range from the edge (see Figure 5) (Unger et al., 2014). A minimum fuzzy overlay type was then used to derive the fuzzy layers for all 17 LCZ types.

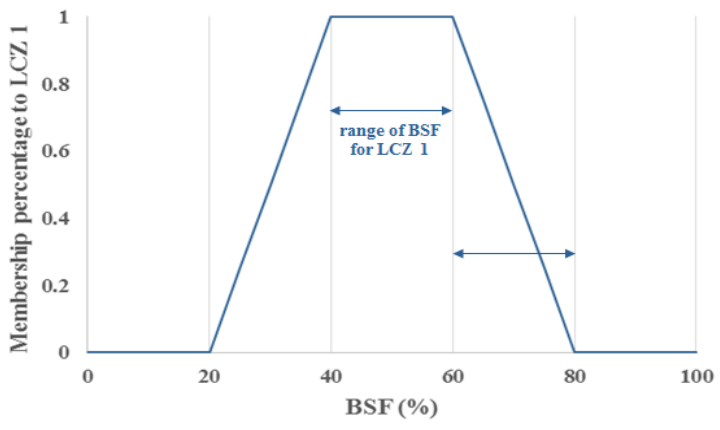

Figure 5. Linear fuzzy membership percentage given a range of value

\subsection{Classification of LCZs by Cellular Automata}

Using the 17 fuzzy membership layers of LCZ types, the LCZ map of Quezon City was generated using a cellular automata approach implemented using Python. The Arcpy library was used for handling raster files and for easier integration as a tool in ArcGIS.

The following were the Cellular Automata rules implemented for all pixels:

\section{Part A. Initial Classification}

1. Per pixel, the LCZ type with the highest membership value was assigned as the primary LCZ type. If a pixel has zero membership for all LCZ types, the primary LCZ type was assigned as unclassified.

2. Per pixel, the LCZ type with the second highest membership was assigned as the secondary LCZ type. If a pixel has zero membership for all LCZ types, the secondary LCZ type was assigned as unclassified.

\section{Part B. Aggregation}

3. If a pixel has only at most 2 neighbors of the same primary LCZ type in its Moore neighborhood, the primary LCZ type of the pixel was assigned from the secondary LCZ type and the secondary LCZ type was assigned from the primary LCZ type. 4. After step 3 and the pixel still has at most 2 neighbors of the same primary LCZ type in its Moore neighborhood, the primary LCZ type of the pixel was assigned from the majority primary LCZ type of the neighborhood. The secondary LCZ type was assigned from the former primary LCZ type.

5. Steps 3 and 4 were iterated 10 times (until clusters of LCZs are visible)

\begin{tabular}{|c|c|c|c|c|c|c|c|c|}
\hline Name & LCZ & PSF (\%) & ISF $(\%)$ & BSF (\%) & $\mathbf{S A}$ & $\begin{array}{c}\text { Building } \\
\text { Height }(\mathbf{m})\end{array}$ & SVF & $\begin{array}{l}\text { Roughness } \\
\text { Length (m) }\end{array}$ \\
\hline Compact high-rise & 1 & $<10$ & $40-60$ & $40-60$ & $0.10-0.20$ & $>=25$ & $0.2-0.4$ & \\
\hline Compact midrise & 2 & $<20$ & $30-50$ & $40-70$ & $0.10-0.20$ & $10-25$ & $0.3-0.6$ & \\
\hline Compact low-rise & 3 & $<30$ & $20-50$ & $40-70$ & $0.10-0.20$ & $3-10$ & $0.2-0.6$ & \\
\hline Open high-rise & 4 & $30-40$ & $30-40$ & $20-40$ & $0.12-0.25$ & $>=25$ & $0.5-0.7$ & \\
\hline Open midrise & 5 & $20-40$ & $30-50$ & $20-40$ & $0.12-0.25$ & $10-25$ & $0.5-0.8$ & \\
\hline Open low-rise & 6 & $30-60$ & $20-50$ & $20-40$ & $0.12-0.25$ & $3-10$ & $0.6-0.9$ & \\
\hline Lightweight low-rise & 7 & $<30$ & $<20$ & $60-90$ & $0.15-0.35$ & $2-4$ & $0.2-0.5$ & \\
\hline Large low-rise & 8 & $<20$ & $40-50$ & $30-50$ & $0.15-0.25$ & $3-10$ & $>0.7$ & \\
\hline Sparsely built & 9 & $60-80$ & $<20$ & $10-20$ & $0.12-0.25$ & $3-10$ & $>0.8$ & \\
\hline Heavy industry & 10 & $40-50$ & $20-40$ & $20-30$ & $0.12-0.20$ & $5-15$ & $0.6-0.9$ & \\
\hline Dense trees & $\mathrm{A}$ & $>90$ & $<10$ & $<10$ & $0.10-0.20$ & & & $>=2$ \\
\hline Scattered trees & $\mathrm{B}$ & $>90$ & $<10$ & $<10$ & $0.15-0.25$ & & & $0.25-0.5$ \\
\hline Bush, scrub & $\mathrm{C}$ & $>90$ & $<10$ & $<10$ & $0.15-0.30$ & & & $0.1-0.25$ \\
\hline Low plants & $\mathrm{D}$ & $>90$ & $<10$ & $<10$ & $0.15-0.25$ & & & $0.03-0.1$ \\
\hline Bare rock or paved & $\mathrm{E}$ & $<10$ & $>90$ & $<10$ & $0.15-0.30$ & & & $0.0002-0.0005$ \\
\hline Bare soil or sand & $\mathrm{F}$ & $>90$ & $<10$ & $<10$ & $0.20-0.35$ & & & $0.0002-0.0005$ \\
\hline Water & $\mathrm{G}$ & $>90$ & $<10$ & $<10$ & $0.02-0.10$ & & & \\
\hline
\end{tabular}

Table 2. Geometric, surface cover, and thermal properties of each LCZ type 


\section{Part C. Detection of Cluster Centers}

6. Clusters large enough to be an LCZ was detected using a $5 \times 5$ square neighborhood window. If a pixel has at least 13 pixels (including itself) within the neighborhood, the pixel is detected as a cluster center. The idea is that an LCZ is a zone of at least $500 \mathrm{~m}$ diameter, and a circle of $500 \mathrm{~m}$ diameter is composed of at least 13 pixels of $100 \mathrm{~m}$ size (see Figure 6).

7. Pixels detected as cluster centers were assigned a final LCZ type same as its primary LCZ type.

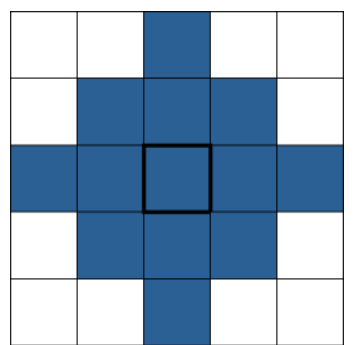

Figure 6. A $5 \times 5$ square neighborhood used for detecting the center of clusters of at least 13 pixel-size

\section{Part D. Zoning}

8. If a pixel still without a final LCZ type has an adjacent cluster center in its Von Neumann neighborhood and the primary LCZ type of the pixel is same as the final LCZ type of the cluster center, the pixel is assigned a final LCZ type same as the cluster center. This was iterated 10 times.

9. If a pixel still without a final LCZ type has an adjacent cluster center in its Von Neumann neighborhood and the secondary LCZ type of the pixel is same as the final LCZ type of the cluster center, the pixel is assigned a final LCZ type same as the cluster center. This was iterated 10 times.

10. If a pixel still does not have a final LCZ type, the final LCZ type was assigned as the majority final LCZ type of the Moore neighborhood pixels. This was iterated 10 times.

\subsection{Validation of LCZs}

The generated LCZ map was validated by means of visual inspection. The LCZ map was overlaid on a satellite image in ArcGIS. Each LCZ type that was generated was cross-checked through the researchers' local knowledge of the area.

\subsection{Evaluation of LCZ map by Land Surface Temperature (LST)}

Daytime and Night-time LST images were processed and downloaded through an online Integrated Development Environment in Google Earth Engine. The images with the least cloud cover were selected and used in the study. A spatial analyst tool was used to obtain the mean value of the land surface temperature within the generated local climate zones.

\section{RESULTS AND DISCUSSION}

\subsection{Fuzzy layers}

The degree of membership for each pixel to each LCZ type was generated and is shown in Figure 7. A white pixel indicates no membership while a brown pixel indicates a possibility or full certainty that the pixel belongs to the LCZ type. It was observed that for most of the LCZ types, the degree of membership ranges from 0 to 1 . It was noted that no pixels were identified to belong under LCZ E (Bare-rock or paved) which was expected since no largely paved areas such as airport runways were identified in the study area using a satellite image. Based from the fuzzy layers, it seems that the study area is mostly composed of low-rise buildings (LCZ 3 and 6) with small portions of medium to highrise buildings. High memberships to dense trees and water were also identified in the watershed area of the city.
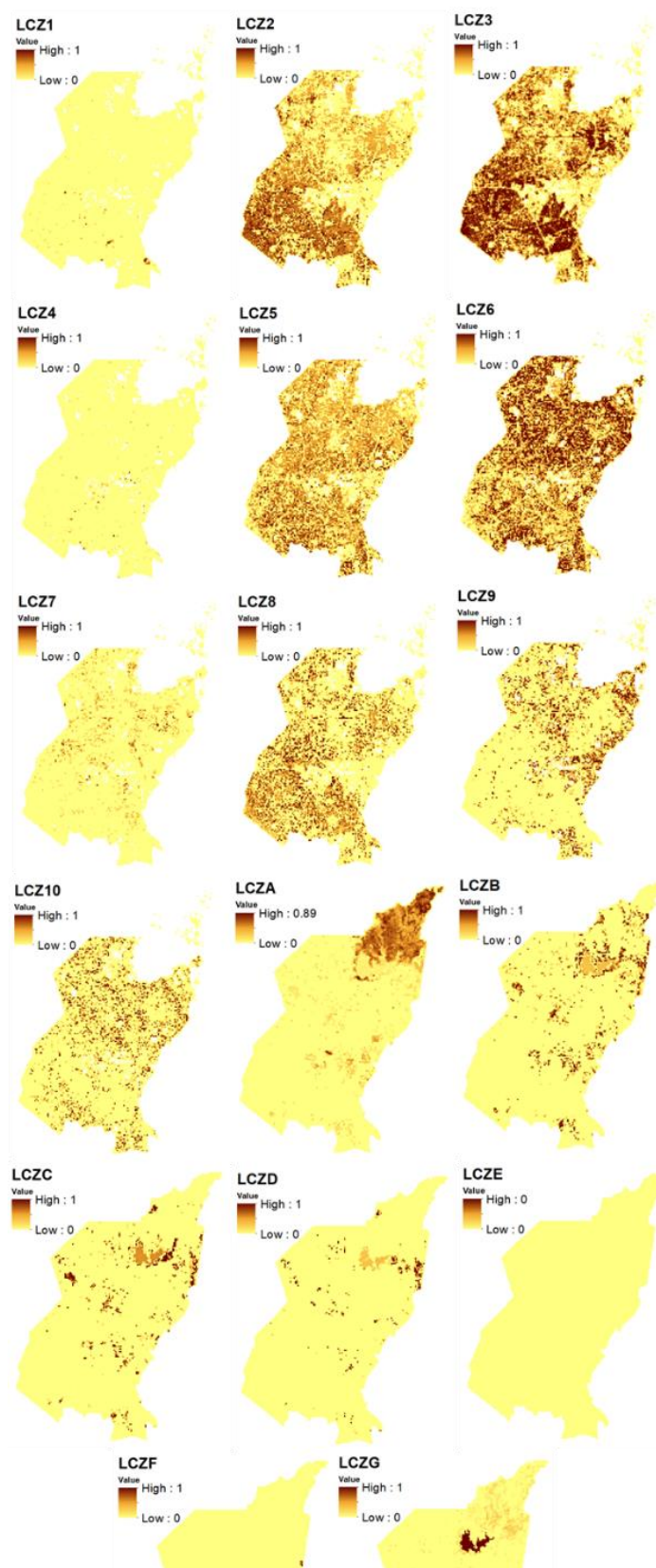

Figure 7. Degree of membership of each pixel to LCZ 1 (Compact high-rise), LCZ 2 (Compact midrise), LCZ 3 (Compact low-rise), LCZ 4 (Open high-rise), LCZ 5 (Open midrise), LCZ 6 (Open low-rise), LCZ 7 (Lightweight low-rise), LCZ 8 (Large low-rise), LCZ 9 (Sparsely built), LCZ 10 (Heavy industry), LCZ A (Dense trees), LCZ B (Scattered trees), LCZ C (Bush, scrub), LCZ D (Low plants), LCZ E (Bare rock or paved), LCZ F ( Bare soil or sand), LCZ G (Water). 


\subsection{LCZ map of Quezon City}

After running the developed tool, the LCZ map of Quezon City was generated (Figure 8). The map shows that seven out of ten built-up LCZs (LCZ 1, 2, 3, 5, 6, 8, 9) and six out of seven land cover LCZs (LCZ A, B, C, D, F, G) were identified in Quezon City, Philippines. It can be observed that LCZ 6 (Open low-rise) dominates the city with an area covering $42.26 \%$ of the city followed by LCZ 3 (Compact low-rise) which covers $29.13 \%$ of the total area of the city. On the other hand, LCZ A (Dense trees) is the largest non-built-up type with an area covering $13.38 \%$ of the city.

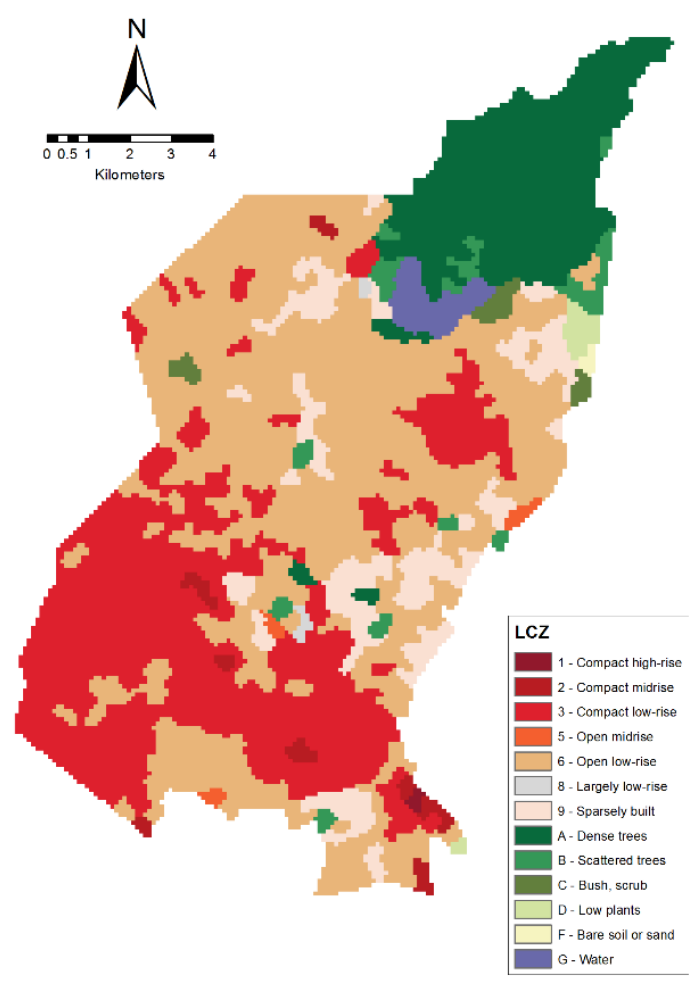

Figure 8. Local Climate Zone map of Quezon City, Philippines

Through visual inspection on a base map, the mapped LCZs were confirmed to match with the features of the city. Shown in Figure 9 are some of the identified areas as shown in satellite image subsets for each LCZ type. A part of Eastwood, which is the business district in the city, was classified under the LCZ 1 (Compact high-rise) wherein a cluster of tall buildings is located. Residential areas were classified in LCZs 3 (Compact low-rise), 5 (Open midrise), 6 (Open low-rise), and 8 (Large low-rise) while LZC 2 (Compact midrise) captured areas which are mostly commercial in use. Though the study area is highly-urbanized, there were still areas that were classified under the land cover LCZ types. Notable areas are the Quezon City Memorial Circle (QCMC), University of the Philippines (UP) Diliman Campus, and the La Mesa Watershed. Portions of UP and La Mesa Watershed were classified under the LCZ A (Dense Trees), but some were under the group of Scattered Trees (LCZ B) together with the QCMC. Barangay Bagong Silangan is composed of three different land cover LCZ types which are LCZ B (Scattered Trees), C (Bush, scrub), and D (Low plants). Lastly, La Mesa Dam was categorized under the LCZ G (Water).

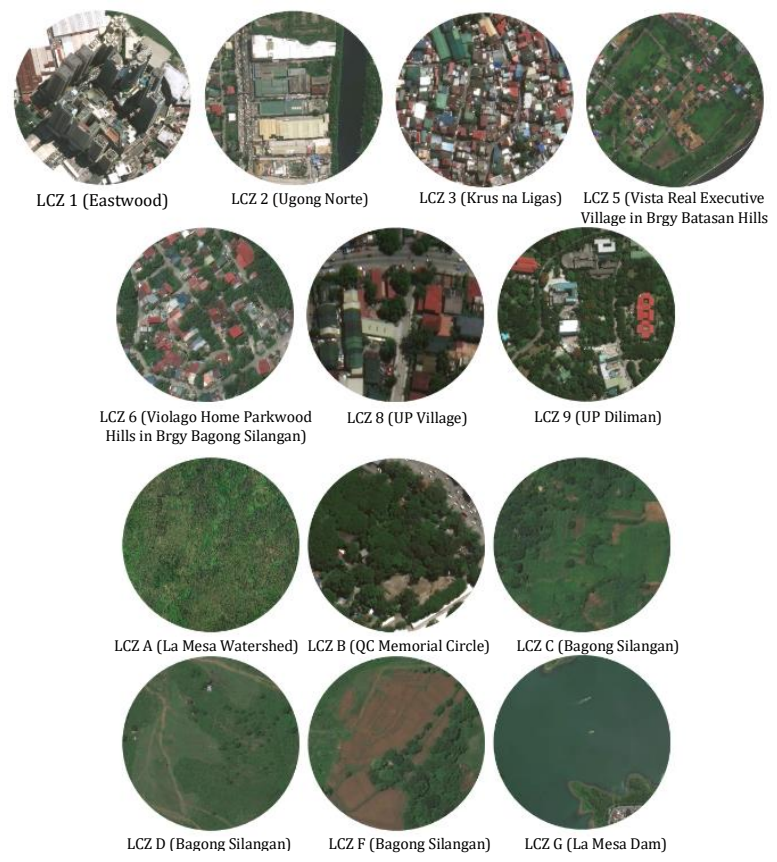

Figure 9. Images of each identified LCZ in Quezon City from ESRI World Imagery Map

\subsection{LST for each LCZ Type}
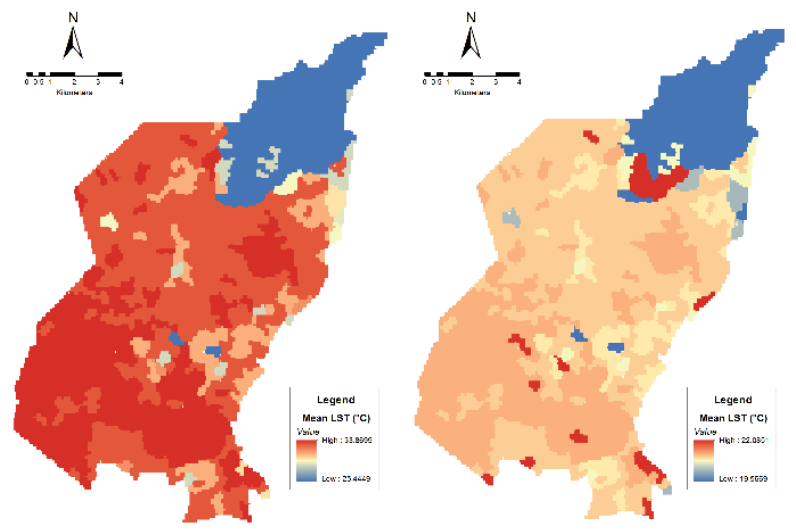

Figure 10. Mean daytime (left) and night-time (right) LST per Local Climate Zone in Quezon City, Philippines

Evidently, mean LST was higher in the daytime with a maximum value of $33.87^{\circ} \mathrm{C}$ as compared to the night-time maximum mean LST of $22.09^{\circ} \mathrm{C}$ (Figure 10). The highest daytime temperature was identified in LCZ 3 (Compact low-rise), which are mostly located in the southern residential portion of Quezon City. Some of the areas which were classified in this type were Krus na Ligas, East and West Kamias, and Kamuning where houses are densely constructed - a factor for localized UHI. The lowest daytime mean temperature was identified in LCZ A (Dense trees) located in UP Diliman Campus and La Mesa Watershed. For the night-time, LCZs 1, 2, 5, and G obtained the highest night-time temperature (visualized as red in night-time LST in Figure 10). The built-types in these areas (LCZs 1,2, and 5) are composed of high to mid-rise buildings that result to more trapping of heat being emitted by building materials at night. LCZ G (Water) displayed high-night time temperature because of its high specific capacity, which result to a slower release of heat at night The lowest night-time mean temperature (visualized as blue in 
night-time LST in Figure 10) was identified in LCZ A (Dense trees) and LCZF (Bare soil or sand).

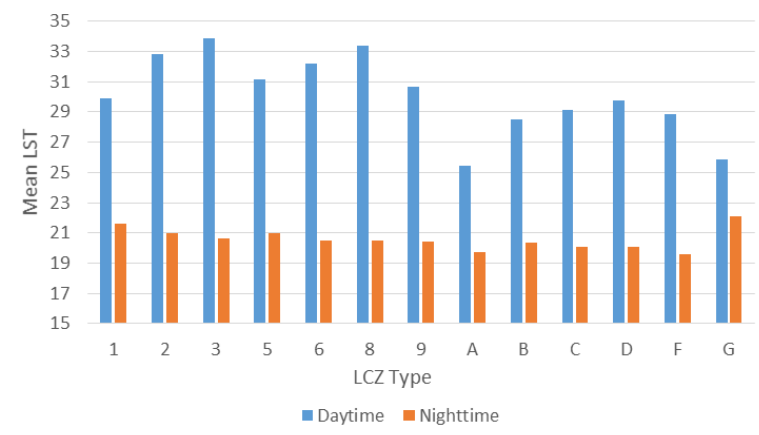

Figure 11. Mean daytime and night-time LST per Local Climate Zone in Quezon City, Philippines

The variations in daytime and night-time LST (Figure 11) showed consistency with profiles from other literature (Yang et al., 2017; Wang et al., 2017; Cai et al., 2018). Earth's surface absorbs heat during the day and radiates it back at night. It occurs in the building material used in the cities to a much greater extent than areas covered in vegetation. This is evident in the higher decrease from the daytime to night-time mean LST values of the LCZ built types (1, 2, 3, 5, 6, 8, and 9). The change in the surface temperature of water is much lower than built types and other land cover types. Excluding water, LCZ 1 (Compact high-rise) was the hottest at night among all LCZ types due to its more heat trapping form. LCZs A (Dense trees) and F (bare soil or sand) were the coolest at night due to more evapotranspiration.

\section{CONCLUSION}

Several methodologies have already been developed to map LCZs. Conventional methods used a remote sensing-based approach where satellite images are classified based on different algorithms. However, these methods rely on local knowledge of the area and may introduce errors in the creation of training areas. Solving this problem, several studies have developed GIS-based LCZ mapping methodologies. These methods use derived geometric, surface, and radiative properties of the LCZs to differentiate the LCZ types. Fuzzy logic or reclassifying techniques are used to generate different layers of LCZ types. A problem with these methods is that the produced LCZ classification has noisy pixels, which needs filtering to smoothen the zones.

To address this problem, this paper developed a GIS-based methodology to map LCZs from seven derived properties using fuzzy logic and a cellular automata-based classification and aggregation algorithm. Results showed that the generated fuzzy layers displayed the membership percentages of a pixel to each LCZ type. Quezon City displayed pixels of high membership to low-rise building types, LCZ 3 and LCZ 6. Produced LCZ map of Quezon City matched with local knowledge of features in the city such as golf courses, open parks, dense tall buildings, and assembly of malls. Thirteen out of $17 \mathrm{LCZ}$ types were identified in the whole city, namely LCZ 1, 2, 3, 5, 6, 8, 9, A, B, C, D, F, and G. The city is mainly composed of LCZ 3 (Compact lowrise) and LCZ 6 (Open low-rise) covering $29.13 \%$ and $42.26 \%$ of the city's total area, respectively.
Assessment of the Land Surface Temperature (LST) profile for each LCZ type for day and night showed consistency such as the highest night temperatures in LCZ 1 (Compact High-Rise) among other built-types and lowest in LCZ A (Dense Trees) and LCZ F (Bare Soil or Sand) in the land cover types.

A GIS toolbox "Local Climate Zones" was also developed which incorporates the fuzzy logic and cellular automata specifications. The toolbox can be easily used to map the LCZs of other cities and just needs the seven derived property layers of the subject area.

\section{ACKNOWLEDGEMENTS}

This research study is part of the output of the Geospatial Assessment and Modelling of Urban Heat Islands in Philippine Cities (Project GUHeat). Project GUHeat is funded by the PCIEERD-DOST with Project No. 4028, 2019 and implemented by UP TCAGP.

\section{REFERENCES}

Algretawee, H., Rayburg, S., Neave, M., 2019. Estimating the effect of park proximity to the central of Melbourne city on Urban Heat Island (UHI) relative to Land Surface Temperature (LST), Ecol. Eng., 138, 374-390, doi.org/10.1016/j.ecoleng.2019.07.034.

Arathyram, R. S., Venugopala Rao, K., 2012. Characterisation of Urban Heat Islands in One of the Most Urbanised Corridors of India from Space Based Multi-Sensor, Spatio -Temporal Data. Proceedings of the 5th International Summer School and Conference of Applied Geoinformatics for Society and Environment, 17-23.

Baldinelli, G., Bonafoni, S., Rotili, A., 2017. Albedo Retrieval From Multispectral Landsat 8 Observation in Urban Environment: Algorithm Validation by in situ Measurements. IEEE J-STARS, 10(10), 4504-4511. doi.org/10.1109/JSTARS.2017.2721549.

Bartesaghi Koc, C., Osmond, P., Peters, A., Irger, M., 2017. Mapping Local Climate Zones for urban morphology classification based on airborne remote sensing data. JURSE 2017, 1-4. doi.org/10.1109/JURSE.2017.7924611.

Bechtel, B., Alexander, P.J., Böhner, J., Ching, J., Conrad, O., Feddema, J., Mills, G., See, L.M., Stewart, I., 2015. Mapping Local Climate Zones for a Worldwide Database of the Form and Function of Cities. ISPRS Int. J. Geo-Information, 4, 199-219. doi.org/10.3390/ijgi4010199.

Cai, M., Ren, C., Xu, Y., Lau, K. K.-L., Wang, R., 2018. Investigating the relationship between local climate zone and land surface temperature using an improved WUDAPT methodology - A case study of Yangtze River Delta, China. Urban Clim., 24, 485-502. doi.org/10.1016/j.uclim.2017.05.010

Fonte, C., Lopes, P., See, L., Bechtel, B., 2019. Using OpenStreetMap (OSM) to enhance the classification of local climate zones in the framework of WUDAPT. Urban Clim., 28. doi.org/10.1016/j.uclim.2019.100456. 
Haashemi, S., Weng, Q., Darvishi, A., \& Alavipanah, S., 2016. Seasonal Variations of the Surface Urban Heat Island in a SemiArid City. Remote Sens., 8(4), 352. doi.org/10.3390/rs8040352.

Hammond, D. S., Chapman, L., Thornes, J. E., 2011. Roughness length estimation along road transects using airborne LIDAR data. Meteorol. Appl., 19, 420-426. doi.org/10.1002/met.273

Stewart, I.D., Oke, T.R., 2012: Local Climate Zones for Urban Temperature Studies. Bull. Amer. Meteor. Soc., 93, 1879-1900. doi.org/10.1175/BAMS-D-11-00019.1.

Tzavali, A., Paravantis, J., Mihalakakou, G., Fotiadi, A., Stigka, El., 2015. Urban Heat Island Intensity: A Literature Review. Fresenius Environ. Bull, 24(12b), 4537-4554.

Unger, J., Lelovics, E., Gál, T.Z., 2014. Local Climate Zone mapping using GIS methods in Szeged. Hungarian $\begin{array}{lll}\text { Geographical Bulletin, } & 63(1), & 29-41 .\end{array}$ doi.org/10.15201/hungeobull.63.1.3
Voogt, J.A., Oke, T.R., 2003. Thermal remote sensing of urban climates. Remote Sens. Environ., 86(3), 370-384. doi.org/10.1016/S0034-4257(03)00079-8.

Wang, Y., Zhan, Q., Wanlu, O., 2017. Impact of Urban Climate Landscape Patterns on Land Surface Temperature in Wuhan, China. Sustainability, 9. doi.org/10.3390/su9101700.

Wang, R., Ren, C., Xu, Y., Lau, K.K.-L., Shi, Y., 2018. Mapping the local climate zones of urban areas by GIS-based and WUDAPT methods: A case study of Hong Kong. Urban Clim., 24, 567-576. doi.org/10.1016/j.uclim.2017.10.001.

Yang, X., Yao, L., Zhu, C., Jin, T., Peng, L.L., 2017. Analysis of Local Heat Islands in Nanjing, China, based on the Local Climate Zone Scheme. Procedia Eng., 205, 2501-2508. doi.org/10.1016/j.proeng.2017.09.980. 